\title{
RETRACTED: Analysis of production affecting factors milkfish (Chanos chanos) in Muna Regency
}

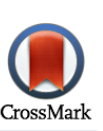

\author{
La Sinaini ${ }^{1 凶}$, Mulyati Azi ${ }^{2}$ \\ ${ }^{1}$ Program Studi Agribisnis, Sekolah Tinggi Ilmu Pertanian Wuna Raha, Indonesia. \\ ${ }^{2}$ Jurusan Agribisnis Perikanan, Sekolah Menengah Kejuruan Negeri 1 Kabangka, Kabupaten Muna, Indonesia.
}

$\begin{array}{ll}\text { ■ Info Artikel: } & \text { ABSTRACT. Following a rigorous, carefully concerns and considered review of the } \\ \text { Diterima: 27 Oktober 2018 } & \text { article published in Akuatikisle: Jurnal Akuakultur, Pesisir dan Pulau-Pulau Kecil to } \\ \text { Disetujui: } 10 \text { November 2018 } & \text { article entitled "Analysis of production affecting factors milkfish (Chanos chanos) in } \\ \text { Dipublikasi: 24 November 2018 } & \text { Muna Regency" Vol 2, No 2, pp. 49-51, November 2018, DOI: } \\ & \text { https://doi.org/10.29239/j.akuatikisle.2.2.49-51. The article contained redundant } \\ \text { M Keyword: } & \text { material, the editor investigated and found that the paper double published in Buletin } \\ \text { RETRACTED Article } & \text { Penelitian Sosial Ekonomi Pertanian Fakultas Pertanian Universitas Haluoleo, Vol. 21, No. } \\ & \text { 2, pp. 75-78, November 2019. DOI: http://dx.doi.org/10.33772/bpsosek.v21i2.7751 }\end{array}$

La Sinaini

Pusat Studi Agribisnis, Sekolah Tinggi Ilmu Pertanian Wuna Raha, Jl. Letjend. Gatot Subroto Km.7 Lasalepa, Raha-

Sulawesi Tenggara, Indonesia 93654

Email: lasinaini81@gmail.com

\begin{abstract}
Following a rigorous, carefully concerns and considered review of the article published in Akuatikisle: Jurnal Akuakultur, Pesisir dan Pulau-Pulau Kecil to (Chanos chanos) in https://doi.org/10.29239/j.akuatikisle.2.2.49-51. The article contained redundant Penelitian Sosial Ekonomi Pertanian Fakultas Pertania
\end{abstract}

The document and its content has been removed from Akuatikisle: Jurnal Akuakultur, Pesisir dan Pulau-Pulau Kecil and reasonable effort should be made to remove all references to this article.

Copyright@ November 2018 Akuatikisle: Jurnal Akuakultur, Pesisir dan Pulau-Pulau Kecil Under Licence a Creative Commons Attribution-ShareAlike 4.0 International License

La Sinaini, Program Studi Agribisnis, Sekolah Tinggi Ilmu Pertanian Wuna Raha, Indonesia. Email lasinaini81@gmail.com

URL Google Scholar: https://scholar.google.co.id/citations?hl=id\&user=IHibHcQAAAAJ

URL Sinta Dikti: http://sinta2.ristekdikti.go.id/authors/detail/?id=5975318\&view=overview

Mulyati Azi, Jurusan Agribisnis Perikanan, Sekolah Menengah Kejuruan Negeri 1 Kabangka, Kabupaten Muna, Indonesia. Email muliatiazi1980@gmail.com

\section{How to cite this article:}

Sinaini, L. \& M. Azi.. 2018. RETRACTED: Analysis of production affecting factors milkfish (Chanos chanos) in Muna Regency. Akuatikisle: Jurnal Akuakultur, Pesisir dan Pulau-Pulau Kecil 2(2): 49-51. DOI: https://doi.org/10.29239/j.akuatikisle.2.2.49-51 